\title{
Evaluating the Effects of Opioid Prescribing Policies on Patient Outcomes in a Safety-net Primary Care Clinic
}

\author{
Christopher L. Rowe, $P h D^{1,2}$ (D), Kellene Eagen, $M D^{3}$, Jennifer Ahern, $P h D^{7}$, \\ Mark Faul, $P h D^{4}$, Alan Hubbard, $P h D^{5}$, and Phillip Coffin, $M D^{2,6}$
}

\begin{abstract}
'Division of Epidemiology, School of Public Health, University of California, Berkeley, Berkeley, CA, USA; ${ }^{2}$ Center on Substance Use and Health, San Francisco Department of Public Health, San Francisco, USA; ${ }^{3}$ Department of Family Medicine and Community Health, School of Medicine and Public Health, University of Wisconsin-Madison, Madison, USA; ${ }^{4}$ Health Systems and Trauma Systems Branch, Centers for Disease Control and Prevention, Atlanta, USA; ${ }^{5}$ Division of Biostatistics, School of Public Health, University of California, Berkeley, Berkeley, USA; ${ }^{6}$ Division of HIV, Infectious Disease \& Global Medicine, University of California San Francisco, San Francisco, USA.
\end{abstract}

BACKGROUND: After decades of liberal opioid prescribing, multiple efforts have been made to reduce reliance upon opioids in clinical care. Little is known about the effects of opioid prescribing policies on outcomes beyond opioid prescribing.

OBJECTIVE: To evaluate the combined effects of multiple opioid prescribing policies implemented in a safety-net primary care clinic in San Francisco, CA, in 2013-2014.

DESIGN: Retrospective cohort study and conditional difference-in-differences analysis of nonrandomized clinic-level policies.

PATIENTS: 273 patients prescribed opioids for chronic non-cancer pain in 2013 at either the treated $(n=151)$ or control clinic $(\mathrm{n}=122)$ recruited and interviewed in 2017 2018.

INTERVENTIONS: Policies establishing standard protocols for dispensing opioid refills and conducting urine toxicology testing, and a new committee facilitating opioid treatment decisions for complex patient cases.

MAIN MEASURES: Opioid prescription (active prescription, mean dose in morphine milligram equivalents [MME]) from electronic medical charts, and heroin and opioid analgesics not prescribed to the patient (any use, use frequency) from a retrospective interview.

KEY RESULTS: The interventions were associated with a reduction in mean prescribed opioid dose in the first three post-policy years (year 1 conditional difference-indifferences estimate: $-52.0 \mathrm{MME}$ [95\% confidence interval: -109.9, -10.6]; year 2: -106.2 MME [-195.0, -34.6]; year 3: -98.6 MME [-198.7, -23.9]; year 4: -72.6 MME $[-160.4,3.6])$. Estimates suggest a possible positive association between the interventions and non-prescribed opioid analgesic use (year 3: 5.2 absolute percentage points $[-0.1,11.2])$ and use frequency (year 3: 0.21 ordinal frequency scale points $[0.00,0.47])$ in the third post-policy year.

CONCLUSIONS: Clinic-level opioid prescribing policies were associated with reduced dose, although the control clinic achieved similar reductions by the fourth postpolicy year, and the policies may have been associated with increased non-prescribed opioid analgesic use.

Received October 20, 2020

Accepted May 6, 2021

Published online June 25, 2021
Clinicians should balance the urgency to reduce opioid prescribing with potential harms from rapid change.

KEY WORDS: opioid prescribing; primary care; illicit opioid use.

J Gen Intern Med 37(1):117-24

DOI: $10.1007 / \mathrm{s} 11606-021-06920-4$

(c) The Author(s) 2021

\section{INTRODUCTION}

The USA continues to grapple with an unprecedented opioid overdose epidemic. Almost half a million people died from opioid-involved drug overdoses from 1999 to 2018, including nearly 50,000 deaths annually in recent years. ${ }^{1,2}$ Although the crisis is now dominated by overdoses involving illicitly manufactured fentanyl, nearly one-third of opioid overdose deaths involved prescription opioids in 2018.,3

Opioid stewardship measures aiming to limit supply and mitigate harms of prescription opioids in primary care settings have been a major component of the national response to the epidemic. $^{4-11}$ Although these measures, including the 2016 Centers for Disease Control and Prevention (CDC) opioid prescribing guidelines, ${ }^{12}$ have corresponded with substantial reductions in opioid prescribing, ${ }^{13-17}$ the rate of prescribing in the USA remains higher than any other nation and varies widely throughout the country. ${ }^{13,18,19}$ Evidence regarding the effects of opioid prescribing policies is largely limited to opioid prescribing outcomes. ${ }^{20-26}$ However, several studies have linked reduction or discontinuation of prescribed opioids to adverse patient outcomes, including dropping out of care, ${ }^{27}$ illicit use of opioids, ${ }^{28,29}$ and death by overdose and suicide. ${ }^{30,31}$ In light of these risks, critical examination of the effects of specific policies on both opioid prescribing and unintended patient outcomes, such as illicit opioid use, is needed to identify strategies that are both effective and safe.

In 2013-2014, a safety-net primary care clinic in San Francisco, CA, implemented policies guiding opioid prescription refills and the use of urine toxicology testing and established a committee to discuss treatment decisions for 
complex patient cases. Understanding the effects of these interventions on opioid prescribing and on unintended negative outcomes can inform opioid prescribing policies and practices.

We used a retrospective cohort design to evaluate the combined effects of these two policies and committee on opioid prescribing, use of heroin, and use of opioid analgesics not prescribed to the patient.

\section{METHODS}

\section{Parent Study}

Data were from a retrospective cohort study of 602 publicly insured patients prescribed opioids for chronic non-cancer pain in San Francisco's safety-net health network. ${ }^{28}$ Eligible participants were $\geq 18$ years old, able to communicate in English, and prescribed opioids for $\geq 3$ months from 2013 to 2015. Participants who were contacted and agreed to participate were seen for a single in-person visit in 2017 or 2018. Additional details regarding the recruitment process are described in the Supplementary Information. Study activities were approved by the University of California San Francisco Institutional Review Board.

\section{Policies Under Study}

The first policy (effective July 1, 2013) outlined procedures for refilling opioid medications when patients requested early or late refills or reported lost or stolen opioid medications. The policy established requirements for increased monitoring and a treatment plan assessment (including possible dose modification) in the case of multiple early refill requests or other concerning behaviors.

The second policy (effective July 1, 2014) required that patients undergo urine toxicology testing prior to initiating opioid therapy and at least annually while continuing therapy. The policy also outlined procedures for when urine toxicology results were inconsistent with prescribed medications (e.g., negative for the prescribed opioid, positive for illicit substances), including a treatment plan assessment and possible opioid discontinuation with a taper.

A new committee began meeting in early 2014 to facilitate multidisciplinary group discussion of patient-centered treatment plans for patients who were prescribed opioids under complex or challenging circumstances (e.g., patients with substance use histories, those prescribed particularly high opioid dosages). The committee was not explicitly tasked with decreasing opioid dose for patients on high doses, but generally provided recommendations to maximize non-opioid treatments and consider dose reduction, especially in high-risk cases.

Because the policies were implemented close together in time, only the combined policy effects are evaluated. Detailed descriptions and documentation for the policies and committee (the interventions) are provided in the Supplementary Information.

\section{Clinics Under Study}

The clinic that implemented the interventions (treated clinic) predominately provided primary care to adults experiencing homelessness, residents of permanent supportive housing, and other members of San Francisco's downtown neighborhoods, which are characterized by concentrated socioeconomic disadvantage and elevated rates of drug overdose mortality. ${ }^{32-34}$

To evaluate the impacts of the interventions among patients at the treated clinic, we leveraged the experience of patients at a control clinic that is in the same network and serves a demographically similar population as the treated clinic, but that did not implement the interventions. We used patients at a clinic that provided integrated primary and specialty care to HIV-infected patients. The control clinic is unique among the network's clinics in that, during a time of both national and local reductions in opioid prescribing, it did not implement formal policies to reduce prescribing, whereas other clinics in the network did. In addition, the control clinic is partially managed by a local university and not subject to the same oversight as other clinics in the network.

\section{Analysis Sample}

The analysis was restricted to patients who were prescribed opioids and receiving care from either the treated or control clinic when the first policy was implemented (July 1, 2013). Patients in the analysis sample were required to have started receiving care from the network on January 1, 2012, or earlier; all retrospective study measures were collected starting January 1,2012 , so this restriction ensured that all patients had complete follow-up during the entire period prior to any policy implementation (i.e., January 1, 2012, through June 30, 2013). Measures from pre-policy period were used to assess trends in outcomes during the pre-policy period as well as to generate baseline covariates for estimating propensity scores.

\section{Study Procedures}

Clinical measures were manually abstracted from electronic medical charts for January 1, 2012, through the date of the study visit. Measures included opioid prescriptions (opioid type, dose, quantity per 30 days), emergency department (ED) visits and their opioid-relatedness, and exposure to opioid stewardship activities (controlled substance monitoring program [CSMP] checks, "yellow flag" behaviors documented by the provider [e.g., early refill requests, suspected diversion], and controlled substance agreements).

Self-reported use frequency of heroin, non-prescribed opioid analgesics, cocaine, methamphetamine, and alcohol was collected for each calendar quarter from 2012 until the date of the study visit through an in-person historical reconstruction interview procedure described in the Supplementary 
Information and elsewhere. ${ }^{28}$ Demographics (e.g., age, education) were also collected at the study visit.

\section{Baseline Covariates}

Baseline covariates included gender, race/ethnicity, age, education, and the following measures corresponding to the full 18-month period prior to the first policy implementation: use of heroin, non-prescribed opioid analgesics, alcohol, methamphetamine, and cocaine; any ED visits; any opioid-related ED visits; any controlled substance agreements; any CSMP checks; any yellow flag behavior indicated by the provider; and mean opioid dose.

\section{Outcomes}

Six study outcomes were assessed for each patient for the 1year pre-policy period (July 1, 2012-June 30, 2013), implementation period (July 1, 2013-June 30, 2014), and three postpolicy periods (July 1, 2014-June 30, 2015; July 1, 2015-June 30, 2016; July 1, 2016-June 30, 2017). We refer to the implementation period and three post-policy periods as the first, second, third, and fourth post-policy periods.

Outcomes included whether the patient had an active opioid prescription on the last day of each period, their mean opioid dose in morphine milligram equivalents (MME; calculated among days the patient was prescribed any opioids), ${ }^{35,36}$ any heroin use and use frequency, and any non-prescribed opioid analgesic use and use frequency. To avoid counting temporary discontinuations of opioid prescriptions, a patient was only considered to not be on opioids at the end of each period if they were not prescribed opioids for a period of at least 3 months including the last day of a period. Use frequency of heroin and non-prescribed opioid analgesics was operationalized as sequential integers ranging from 0 to 6 corresponding to none, once, intermittently, less than weekly or weekly, multiple times per week, and daily or nearly daily. Since these measures were collected quarterly, we used the maximum value within each post-policy period.

All patients were included in the analysis for all outcomes and post-policy periods, except for the mean MME outcome. For this outcome, patients who were not prescribed opioids during a post-policy period were excluded from the analysis for the post-policy period.

\section{Statistical Analysis}

Associations between the interventions and each of the six outcomes were assessed using a conditional difference-indifferences approach, which incorporates propensity score weighting to balance covariates that may be associated with differential outcome dynamics among the treated and control groups. ${ }^{37}$ Additional details are provided in the Supplementary Information.

We used logistic regression to estimate propensity scores using all baseline covariates, which we hypothesized may impact outcome trends, as independent variables. To assess covariate balance achieved via propensity scores, baseline characteristics of treated and control groups were compared using standardized mean differences (SMDs) in the original sample and after weighting each patient by the inverse estimated probability of receiving their observed treatment. ${ }^{38}$

We applied the conditional difference-in-differences weighting estimator to each outcome and post-policy period and calculated $95 \%$ bootstrap confidence intervals using the percentile method with 2000 iterations.

We conducted a sensitivity analysis using alternative specifications for the propensity score models, which is described in the Supplementary Information.

\section{RESULTS}

\section{Sample Characteristics}

The analysis included $151(55 \%)$ treated clinic patients and $122(45 \%)$ control clinic patients. Patient characteristics by clinic are presented in Table 1.

\section{Covariate Balance}

There were substantial reductions in the SMDs of baseline covariates between treated and control groups after weighting by the inverse probability of treatment received (Supplemental Table 1). However, 3 out of 20 covariates had SMDs $>10$ after weighting: having a bachelor's degree or higher (12.0), any ED visit (-10.8), and any opioid-related ED visit (-10.7).

\section{Conditional Difference-in-Differences Estimates}

The interventions were associated with a reduction in mean opioid dose in the first three post-policy years (year 1 conditional difference-in-differences estimate: $-52.0 \mathrm{MME}[95 \%$ confidence interval: $-109.9,-10.6]$; year 2 : $-106.2 \mathrm{MME}$ $[-195.0,-34.6]$; year 3: $-98.6 \mathrm{MME}[-198.7,-23.9]$; year 4: -72.6 MME $[-160.4,3.6]$ ) (Table 2 and Fig. 1). The analysis for this outcome included 273, 260, 248, and 239 patients who were prescribed opioids for at least 1 day during post-policy periods one to four, respectively.

There was no evidence that the combined interventions were associated with whether patients were prescribed opioids at the end of each period (Supplemental Figure 2) or heroin use or use frequency (Supplemental Figures 3-4).

Although confidence intervals included the null, estimates suggested a possible positive association between the combined interventions and non-prescribed opioid analgesic use (year 3: 5.2 absolute percentage points $[-0.1,11.2]$ ) and use frequency (year 3: 0.21 ordinal frequency scale points $[0.00$, $0.47]$ ) in the third post-policy year (Supplemental Figures 5$6)$.

Sensitivity analysis results were largely consistent with the main results and are presented in Supplemental Table 2. 
Table 1 Patient Characteristics by Clinic

\begin{tabular}{|c|c|c|c|c|c|c|}
\hline \multirow[t]{2}{*}{ Patient characteristics } & \multicolumn{2}{|c|}{$\begin{array}{l}\text { Entire sample } \\
(n=273)\end{array}$} & \multicolumn{2}{|c|}{$\begin{array}{l}\text { Treated clinic } \\
(n=151)\end{array}$} & \multicolumn{2}{|c|}{$\begin{array}{l}\text { Control clinic } \\
(n=122)\end{array}$} \\
\hline & $\mathbf{n}$ & $\%$ & $\mathbf{n}$ & $\%$ & $\mathbf{n}$ & $\%$ \\
\hline Age, mean (SD) & 51.4 & 8.5 & 52.5 & 8.0 & 49.9 & 8.9 \\
\hline \multicolumn{7}{|l|}{ Gender } \\
\hline Male & 175 & 64.1 & 86 & 57.0 & 89 & 73.0 \\
\hline Female & 77 & 28.2 & 51 & 33.8 & 26 & 21.3 \\
\hline Transgender or other & 21 & 7.7 & 14 & 9.3 & 7 & 5.7 \\
\hline \multicolumn{7}{|l|}{ Race } \\
\hline Non-Hispanic white & 95 & 34.8 & 58 & 38.4 & 37 & 30.3 \\
\hline Non-Hispanic black & 99 & 36.3 & 56 & 37.1 & 43 & 35.2 \\
\hline Hispanic & 38 & 13.9 & 13 & 8.6 & 25 & 20.5 \\
\hline Non-Hispanic other/mixed race & 41 & 15.0 & 24 & 15.9 & 17 & 13.9 \\
\hline \multicolumn{7}{|l|}{ Education } \\
\hline Less than high school & 63 & 23.1 & 35 & 23.2 & 28 & 23.0 \\
\hline High school graduate & 87 & 31.9 & 52 & 34.4 & 35 & 28.7 \\
\hline Some college, associate's degree, or vocational training & 94 & 34.4 & 49 & 32.5 & 45 & 36.9 \\
\hline Bachelor's degree or higher & 29 & 10.6 & 15 & 9.9 & 14 & 11.5 \\
\hline HIV positive & 141 & 51.6 & 24 & 15.9 & 117 & 95.9 \\
\hline Mean pre-policy opioid dose (MME), mean (SD) & 269.9 & 549.0 & 264.8 & 490.9 & 276 & 615.5 \\
\hline Any pre-policy heroin use & 29 & 10.6 & 18 & 11.9 & 11 & 9.0 \\
\hline Any pre-policy non-prescribed opioid analgesic use & 40 & 14.7 & 25 & 16.6 & 15 & 12.3 \\
\hline Any pre-policy alcohol use & 155 & 56.8 & 83 & 55.0 & 72 & 59.0 \\
\hline Any pre-policy cocaine use & 73 & 26.7 & 38 & 25.2 & 35 & 28.7 \\
\hline Any pre-policy methamphetamine use & 47 & 17.2 & 29 & 19.2 & 18 & 14.8 \\
\hline Any pre-policy emergency department visits & 103 & 37.7 & 60 & 39.7 & 43 & 35.2 \\
\hline Any pre-policy opioid-related emergency department visits & 34 & 12.5 & 17 & 11.3 & 17 & 13.9 \\
\hline Any pre-policy controlled substance agreements & 40 & 14.7 & 30 & 19.9 & 10 & 8.2 \\
\hline Any pre-policy yellow flag behaviors & 80 & 29.3 & 49 & 32.5 & 31 & 25.4 \\
\hline Any pre-policy CSMP checks & 10 & 3.7 & 9 & 6.0 & 1 & 0.8 \\
\hline
\end{tabular}

\section{DISCUSSION}

We found that the interventions were associated with reductions in opioid dose in the first 3 years and possibly with increases in non-prescribed opioid analgesic use. There was no evidence that the interventions were associated with changes in the overall proportion of patients prescribed opioids or in heroin use.

The interventions were associated with over a $100 \mathrm{MME}$ reduction (40\% relative change from the pre-intervention dose), which brought the mean opioid dose among treated clinic patients below $200 \mathrm{MME}$, a dose deemed high-risk and targeted for reduction by policies at the Veterans Administration Health System. ${ }^{39}$ The interventions did not have the explicit aim of reducing patients' opioid dose but rather aimed to mitigate concerning patient behavior and improve safety. Our findings suggest that policies guided by this strategy may provide an effective approach for reducing opioid dose among patients receiving opioid therapy.
The dose reductions were greatest in the second and third post-policy years but were largely attenuated by the fourth year. The declining trend in opioid dose among control clinic patients suggests that secular trends in opioid prescribing may have caught up to reductions achieved by the interventions. Although the control clinic did not implement specific opioid prescribing policies, our study period overlaps with several trends and policies that likely affected prescribing trends at both the treated and control clinics. There were national reductions in prescribed opioid dose during this time, ${ }^{16,17}$ which were likely driven by an increasing awareness of the risks associated with prescription opioids ${ }^{40-44}$ and further influenced by the release of the CDC's prescribing guidelines in 2016. ${ }^{14}$ There were also several state and local changes that aimed to promote safer opioid prescribing during this period (details provided in the Supplementary Information). Our results suggest that these changes, among others, were sufficient to gradually reduce the prescribed opioid dose without

Table 2 Conditional Difference-in-Differences Estimates for the Association Between Opioid Prescribing Interventions and Patient Outcomes

\begin{tabular}{|c|c|c|c|c|c|c|c|c|}
\hline \multirow[t]{2}{*}{ Patient outcome } & \multicolumn{2}{|c|}{ Year 1} & \multicolumn{2}{|l|}{ Year 2} & \multicolumn{2}{|c|}{ Year 3} & \multicolumn{2}{|c|}{ Year 4} \\
\hline & Est. & $95 \%$ CI & Est. & $95 \%$ CI & Est. & $95 \% \mathrm{CI}$ & Est. & $95 \%$ CI \\
\hline Opioid prescription (absolute \%) & 3.5 & $-8.4,22.5$ & & $-11.7,22.0$ & 6.6 & $-6.3,27.2$ & & $-12.3,24.5$ \\
\hline Mean opioid dose (MME) & -52.0 & $-109.9,-10.6$ & -106.2 & $-195.0,-34.6$ & -98.6 & $-198.7,-23.9$ & -72.6 & $-160.4,3.6$ \\
\hline \multicolumn{9}{|l|}{ Heroin use } \\
\hline Any use (absolute \%) & 1.2 & $-3.7,6.6$ & 0.9 & $-4.6,7.1$ & -0.4 & $-8.9,8.8$ & 2.3 & $-4.2,11.6$ \\
\hline Frequency of use (ordinal use scale) & 0.06 & $-0.10,0.23$ & 0.03 & $-0.16,0.23$ & 0.06 & $-0.24,0.53$ & 0.1 & $-0.19,0.48$ \\
\hline \multicolumn{9}{|l|}{ Non-prescribed opioid analgesic use } \\
\hline Any use (absolute \%) & 1.3 & $-1.3,4.0$ & 3.0 & $-1.9,9.6$ & 5.2 & $-0.1,11.2$ & 4.6 & $-5.0,13.1$ \\
\hline Frequency of use (ordinal use scale) & 0.03 & $-0.07,0.13$ & 0.14 & $-0.09,0.41$ & 0.21 & $0.00,0.47$ & 0.12 & $-0.16,0.41$ \\
\hline
\end{tabular}




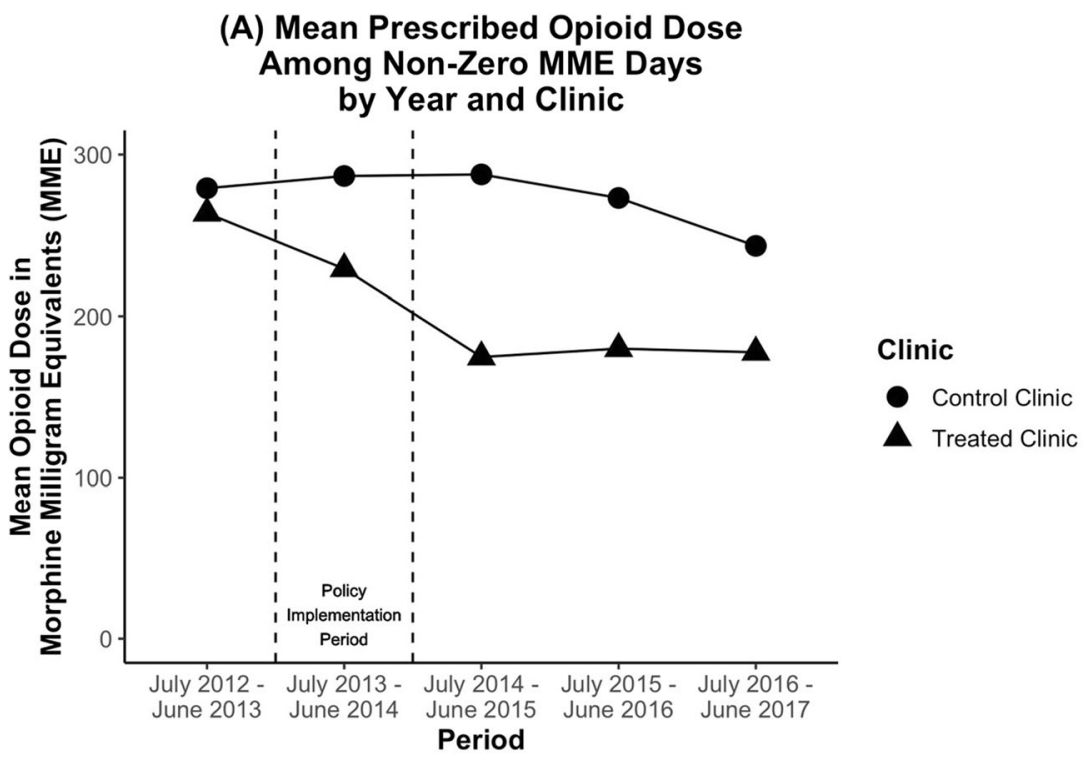

(B) Difference in Differences Estimates

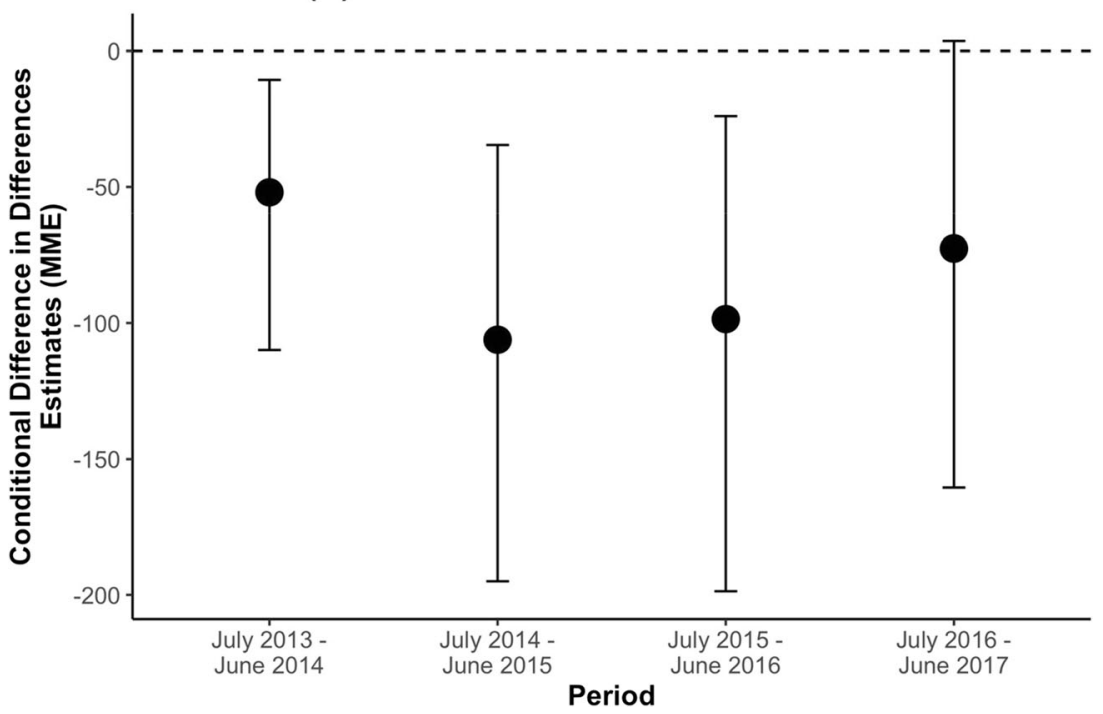

Figure 1 A Outcome trends by clinic and B conditional difference-in-differences estimates for the mean opioid dose outcome.

the explicit interventions implemented at the treated clinic, though not with the rapidity achieved by the interventions.

There was no association between the interventions and the proportion of patients prescribed opioids. However, to participate in the parent study, patients were required to complete an in-person visit in either 2017 or 2018, which may have systematically excluded patients who had dropped out of care, died, or been otherwise difficult to locate since the interventions were implemented in 2013-2014. Opioid discontinuation and dose reductions have been linked to both dropping out of care ${ }^{27}$ and mortality, ${ }^{30,31}$ suggesting the possibility that patients who had their opioids discontinued may be underrepresented in our sample. An unpublished quality improvement analysis conducted at the treated clinic found a $52 \%$ reduction in the number of patients on long-term opioid therapy from 2012 to 2015 , which is substantially larger than the $15 \%$ reduction observed among our treated clinic sample over a similar time frame. ${ }^{45}$ This difference suggests that patients who had their opioids discontinued are under-represented in our treated clinic sample; unfortunately, we have no way to make a similar assessment for our control clinic sample. However, under the assumption that undersampling of opioid-discontinued patients occurred at the same rate across the treated and control clinics, our estimate of a true effect would be biased towards the null. Thus, our null effect estimate for this measure should be interpreted with caution. To mitigate the threat of such biases, it is important that future studies evaluate opioid prescribing policies using entire populations of interest or truly representative samples.

The results were suggestive of a positive association between the interventions and use of non-prescribed opioid analgesics, although confidence intervals included the null. It is notable that use of non-prescribed opioid analgesics increased among both treated and control clinics. From 2015 
to 2019, national estimates of past year misuse of pain relievers declined ${ }^{46,47}$ However, to our knowledge, no studies have assessed trends in non-prescribed opioid analgesic use among patients prescribed opioids during this period; thus, it is unclear whether the trends observed in our sample are generalizable to other populations or unique to the clinics under study. However, multiple studies have linked prescription opioid discontinuation with adverse patient outcomes, including mortality and heroin use. ${ }^{28-31} \mathrm{~A}$ study among the entire parent study sample observed associations between opioid discontinuations and dose reductions and non-prescribed opioid analgesic use, ${ }^{28}$ which is consistent with our findings that the interventions under study may have increased the use of non-prescribed opioid analgesics. Also, the treated clinic implemented an integrative pain management program to advance the use of multimodal pain treatments in 2016, which was associated with self-reported improvements in pain, social satisfaction, and mental health outcomes among participating patients. ${ }^{48}$ It is plausible that this program and its benefits could have attenuated any adverse impacts of the interventions on non-prescribed opioid use. Regardless, our findings highlight the importance of carefully weighing the potential benefits and harms associated with reducing or discontinuing opioid therapy for individual patients. ${ }^{49}$

The present study has several limitations. First, our convenience sample may not be representative of the entire patient population among the two clinics over the course of the study period. Importantly, our study design required patients to complete an in-person interview at the end of the retrospective study period, which may have systematically exclude patients who dropped out of care or died. Second, our measures of illicit opioid use were obtained via retrospective self-report and thus vulnerable to reporting biases. Third, the patients under study are socioeconomically disadvantaged and have higher rates of substance use and HIV relative to the general population and thus the estimated impacts of these policies may not be generalizable to other patient populations. Fourth, the validity of the conditional difference-in-differences estimator depends on the assumption that any differences in outcome trends not attributable to the treatment are attributable to baseline characteristics that we observed and were able to balance across treated and control clinics using propensity scores, which is not directly testable. Related to this, our propensity score approach did not balance the prevalence of having a bachelor's degree or higher, or experiencing an ED visit or opioid-related ED visit during the pre-policy period. However, after weighting, the treated clinic patients exhibited a higher prevalence of having a bachelor's degree or higher, and lower baseline prevalences of ED visits and opioid-related ED visits relative to control clinic patients. If these covariates were correlated with post-intervention outcome trends, this imbalance would suggest a lower-risk treated population and we anticipate a bias towards the null. Specifically, the weighted treated sample has a risk profile that makes them less likely, relative to the weighted control sample, to experience a dose reduction or to increase use of non-prescribed opioid analgesics in the absence of the interventions. Lastly, our analytic approach and choice of control group assume that outcome trends are independent of HIV status, conditional on other observed patient characteristics. Although levels of outcomes may differ by HIV status, we have no reason to expect trends in outcomes to differ after accounting for other demographic and clinical characteristics.

Despite these limitations, the present study offers a rigorous evaluation of the effects of specific opioid prescribing policies on opioid prescribing and illicit opioid use. Among this sample, we found that policies addressing concerning behavior, such as multiple early refill requests or abnormal urine toxicology results, and a patient-centered committee designed to facilitate challenging treatment decisions were associated with a substantial reduction in mean opioid dose and possibly with an increase in non-prescribed opioid analgesic use. Such empirical evidence is essential for informing the path forward as we seek a balance between reducing opioid prescribing and minimizing harms for affected patients.

Corresponding Author: Christopher L. Rowe, PhD; Division of Epidemiology, School of Public Health, University of California, Berkeley, Berkeley, CA, USA (e-mail: chrisrowe@berkeley.edu).

Supplementary Information The online version contains supplementary material available at https://doi.org/10.1007/s11606-02106920-4.

Funding This study was funded by National Institute on Drug Abuse (NIDA) grant K24DA042720 and Centers for Disease Control and Prevention (CDC) grant UO1CE002793.

\section{Declarations:}

Conflict of Interest: MF is employed by the Centers for Disease Control and Prevention, which funded this work. The authors declare no other conflicts.

Open Access This article is licensed under a Creative Commons Attribution 4.0 International License, which permits use, sharing, adaptation, distribution and reproduction in any medium or format, as long as you give appropriate credit to the original author(s) and the source, provide a link to the Creative Commons licence, and indicate if changes were made. The images or other third party material in this article are included in the article's Creative Commons licence, unless indicated otherwise in a credit line to the material. If material is not included in the article's Creative Commons licence and your intended use is not permitted by statutory regulation or exceeds the permitted use, you will need to obtain permission directly from the copyright holder. To view a copy of this licence, visit http://creativecommons. org/licenses/by/4.0/.

\section{REFERENCES}

1. Centers for Disease Control and Prevention National Center for Health Statistics. Multiple Cause of Death 1999-2018 on CDC WONDER Online Database, released 2019. Published online March 17, 2018. http:// wonder.cdc.gov/

2. Hedegaard H, Minaño AM, Warner M. Drug Overdose Deaths in the United States, 1999-2018. National Center for Health Statistics; 2020. 
3. Wilson N, Kariisa M, Seth $\mathbf{P}$, Smith H, Davis NL. Drug and OpioidInvolved Overdose Deaths - United States, 2017-2018. MMWR Morb Mortal Wkly Rep. 2020;69(11):290-297. https://doi.org/10.15585/ mmwr.mm6911a4

4. Strickler GK, Zhang K, Halpin JF, Bohnert ASB, Baldwin GT, Kreiner PW. Effects of mandatory prescription drug monitoring program (PDMP) use laws on prescriber registration and use and on risky prescribing. Drug Alcohol Depend. 2019;199:1-9. https://doi.org/10.1016/j. drugalcdep.2019.02.010

5. Shev AB, Wintemute GJ, Cerda M, Crawford A, Stewart SL, Henry SG. Prescription Drug Monitoring Program: Registration and Use by Prescribers and Pharmacists Before and After Legal Mandatory Registration, California, 2010-2017. Am J Public Health. 2018;108(12):1669-1674. doi:https://doi.org/10.2105/AJPH.2018.304704

6. Kay C, Wozniak E, Ching A, Bernstein J. Pain Agreements and Healthcare Utilization in a Veterans Affairs Primary Care Population: A Retrospective Chart Review. Pain Ther. 2018;7(1):121-126. doi:https:// doi.org/10.1007/s40122-018-0098-5

7. Penko J, Mattson J, Miaskowski C, Kushel M. Do patients know they are on pain medication agreements? Results from a sample of high-risk patients on chronic opioid therapy. Pain Med. 2012;13(9):1174-1180. doi:https://doi.org/10.1111/j.1526-4637.2012.01430.x

8. Pergolizzi JV, Curro FA, Col N, et al. A multicentre evaluation of an opioid patient-provider agreement. Postgrad Med J. 2017;93(1104):613617. doi:https://doi.org/10.1136/postgradmedj-2016-134607

9. Mahajan G. Role of Urine Drug Testing in the Current Opioid Epidemic Anesth Analg. 2017;125(6):2094-2104. doi:https://doi.org/10.1213/ ANE.0000000000002565

10. Pergolizzi J, Pappagallo M, Stauffer J, et al. The role of urine drug testing for patients on opioid therapy. Pain Pract. 2010;10(6):497-507. doi:https://doi.org/10.1111/j.1533-2500.2010.00375.x

11. Von Korff M, Dublin S, Walker RL, et al. The Impact of Opioid Risk Reduction Initiatives on High-Dose Opioid Prescribing for Patients on Chronic Opioid Therapy. J Pain. 2016;17(1):101-110. doi:https://doi org/10.1016/j.jpain.2015.10.002

12. Dowell D, Haegerich TM, Chou R. CDC Guideline for Prescribing Opioids for Chronic Pain - United States, 2016. MMWR Recomm Rep. 2016;65(1): 1-49. https://doi.org/10.15585/mmwr.rr6501el

13. Centers for Disease Control and Prevention. U.S. Opioid Prescribing Rate Maps. Accessed March 27, 2020. https://www.cdc.gov/drugoverdose/ maps/rxrate-maps.html

14. Bohnert ASB, Guy GP Jr, Losby JL. Opioid Prescribing in the United States Before and After the Centers for Disease Control and Prevention's 2016 Opioid Guideline. Ann Intern Med. 2018;169(6):367-375. doi:https://doi.org/10.7326/M18-1243

15. Fenton JJ, Agnoli AL, Xing G, et al. Trends and Rapidity of Dose Tapering Among Patients Prescribed Long-term Opioid Therapy, 20082017. JAMA Netw Open. 2019;2(11):e1916271. doi:https://doi.org/10. 1001/jamanetworkopen.2019.16271

16. Guy GP, Zhang K, Bohm MK, et al. Vital Signs: Changes in Opioid Prescribing in the United States, 2006-2015. MMWR Morb Mortal Wkly Rep. 2017;66(26):697-704. https://doi.org/10.15585/mmwr. mm6626a4

17. Strickler GK, Kreiner PW, Halpin JF, Doyle E, Paulozzi LJ. Opioid Prescribing Behaviors - Prescription Behavior Surveillance System, 11 States, 2010-2016. MMWR Surveill Summ. 2020;69(1):1-14. https://doi. org/10.15585/mmwr.ss690lal

18. Schieber LZ, Guy GP, Seth P, et al. Trends and Patterns of Geographic Variation in Opioid Prescribing Practices by State, United States, 20062017. JAMA Netw Open. 2019;2(3):e190665. doi:https://doi.org/10. 1001/jamanetworkopen.2019.0665

19. International Narcotics control Board. Narcotic Drugs 2019, Estimated World Requirements for 2020, Statistics for 2018. https://www.incb.org/

20. Shoemaker-Hunt SJ, Wyant BE. The Effect of Opioid Stewardship Interventions on Key Outcomes: A Systematic Review. J Patient Saf. 2020;16(3):S36-S41. doi:https://doi.org/10.1097/PTS 0000000000000710

21. Losby JL, Hyatt JD, Kanter MH, Baldwin G, Matsuoka D. Safer and more appropriate opioid prescribing: a large healthcare system's comprehensive approach. J Eval Clin Pract. 2017;23(6):1173-1179. doi:https:// doi.org/10.1111/jep. 12756

22. Mears, MD, PhD SC, Shnaekel, MD, MPH A, Wilkinson, MD J, Chen, BS C, Barnes, MD CL. A departmental policy can reduce opioid prescribing after orthopedic surgery. $J$ of Opioid Management. 2020;16(1):41-47. doi:https://doi.org/10.5055/jom.2020.0549
23. Lin LA, Bohnert ASB, Kerns RD, Clay MA, Ganoczy D, Igen MA Impact of the Opioid Safety Initiative on opioid-related prescribing in veterans. Pain. 2017;158(5):833-839. doi:https://doi.org/10.1097/j. pain.0000000000000837

24. Chacko J, Greenstein J, Ardolic B, Berwald N. Effect of an emergency department opioid prescription policy on prescribing patterns. The American Journal of Emergency Medicine. 2017;35(9):1327-1329. doi:https://doi.org/10.1016/j.ajem.2017.06.024

25. Osborn SR, Yu J, Williams B, Vasilyadis M, Blackmore CC. Changes in Provider Prescribing Patterns After Implementation of an Emergency Department Prescription Opioid Policy. The Journal of Emergency Medicine. 2017;52(4):538-546. doi:https://doi.org/10.1016/j.jemermed. 2016.07.120

26. Meisenberg BR, Grover J, Campbell C, Korpon D. Assessment of Opioid Prescribing Practices Before and After Implementation of a Health System Intervention to Reduce Opioid Overprescribing. JAMA Netw Open. 2018;1(5):e182908. doi:https://doi.org/10.1001/jamanetworkopen. 2018.2908

27. Perez HR, Buonora M, Cunningham CO, Heo M, Starrels JL. Opioid Taper Is Associated with Subsequent Termination of Care: a Retrospective Cohort Study. J Gen Intern Med. 2020;35(1):36-42. doi:https://doi.org/ 10.1007/s11606-019-05227-9

28. Coffin PO, Rowe C, Oman N, et al. Illicit opioid use following changes in opioids prescribed for chronic non-cancer pain. Fischer G, ed. PLOS ONE. 2020;15(5):e0232538. https://doi.org/10.1371/journal.pone.0232538

29. Binswanger IA, Glanz JM, Faul M, et al. The Association between Opioid Discontinuation and Heroin Use: A Nested Case-Control Study. Drug Alcohol Depend. 2020;217:108248. doi:https://doi.org/10.1016/j. drugalcdep.2020.108248

30. James JR, Scott JM, Klein JW, et al. Mortality After Discontinuation of Primary Care-Based Chronic Opioid Therapy for Pain: a Retrospective Cohort Study. J Gen Intern Med. 2019;34(12):2749-2755. doi:https://doi. org/10.1007/s11606-019-05301-2

31. Oliva EM, Bowe T, Manhapra A, et al. Associations between stopping prescriptions for opioids, length of opioid treatment, and overdose or suicide deaths in US veterans: observational evaluation. BMJ. 2020;368:m283. doi:https://doi.org/10.1136/bmj.m283

32. Davidson PJ, McLean RL, Kral AH, Gleghorn AA, Edlin BR, Moss AR. Fatal heroin-related overdose in San Francisco, 1997-2000: a case for targeted intervention. J Urban Health. 2003;80(2):261-273. doi:https:// doi.org/10.1093/jurban/jtg029

33. Visconti AJ, Santos G-M, Lemos NP, Burke C, Coffin PO. Opioid Overdose Deaths in the City and County of San Francisco: Prevalence, Distribution, and Disparities. J Urban Health. 2015;92(4):758-772. doi:https://doi.org/10.1007/s11524-015-9967-y

34. Chang JS. Health in the Tenderloin: A resident-guided study of substance use, treatment, and housing. Soc Sci Med. 2017;176:166174. doi:https://doi.org/10.1016/j.socscimed.2017.01.014

35. Centers for Disease Control and Prevention. Calculating Total Daily Dose of Opioids for Safer Dosage. Published online August 28, 2019. Accessed May 12, 2020. https://www.cdc.gov/drugoverdose/pdf/calculating_total_daily_dose-a.pdf

36. Von Korff $\mathbf{M}$, Korff $\mathbf{M V}$, Saunders $\mathbf{K}$, et al. De facto long-term opioid therapy for noncancer pain. Clin J Pain. 2008;24(6):521-527. doi:https:// doi.org/10.1097/AJP.0b013e318169d03b

37. Abadie A. Semiparametric Difference-in-Differences Estimators. Review of Economic Studies. 2005;72:1-19.

38. Austin PC, Stuart EA. Moving towards best practice when using inverse probability of treatment weighting (IPTW) using the propensity score to estimate causal treatment effects in observational studies. Stat Med. 2015;34(28):3661-3679. doi:https://doi.org/10.1002/sim.6607

39. Westanmo A, Marshall P, Jones E, Burns K, Krebs EE. Opioid Dose Reduction in a VA Health Care System-Implementation of a Primary Care Population-Level Initiative. Pain Med. 2015;16(5):1019-1026. doi:https:// doi.org/10.1111/pme.12699

40. Dunn KM, Saunders KW, Rutter CM, et al. Opioid prescriptions for chronic pain and overdose: a cohort study. Ann Intern Med. 2010;152(2):85-92. doi:https://doi.org/10.7326/0003-4819-152-2201001190-00006

41. Bohnert ASB, Valenstein M, Bair MJ, et al. Association between opioid prescribing patterns and opioid overdose-related deaths. JAMA. 2011;305(13):1315-1321. doi:https://doi.org/10.1001/jama.2011.370

42. Gomes T, Mamdani MM, Dhalla IA, Paterson JM, Juurlink DN. Opioid dose and drug-related mortality in patients with nonmalignant pain. Arch Intern Med. 2011;171(7):686-691. doi:https://doi.org/10.1001/ archinternmed.2011.117 
43. Centers for Disease Control and Prevention (CDC). Vital signs: overdoses of prescription opioid pain relievers-United States, 1999-2008. MMWR Morb Mortal Wkly Rep. 2011;60(43):1487-1492.

44. Okie S. A flood of opioids, a rising tide of deaths. $N$ Engl $J$ Med. 2010;363(21): 1981-1985. doi:https://doi.org/10.1056/NEJMp1011512

45. Eagen K. Personal Communication.; 2020.

46. Center for Behavioral Health Statistics and Quality. Results from the 2015 National Survey on Drug Use and Health: Detailed Tables. Substance Abuse and Mental Health Services Administration; 2016. https://www. samhsa.gov/data/

47. Center for Behavioral Health Statistics and Quality. Results from the 2019 National Survey on Drug Use and Health: Detailed Tables. Substance Abuse and Mental Health Services Administration; 2020. https://www. samhsa.gov/data/
48. Chao MT, Hurstak E, Leonoudakis-Watts K, et al. Patient-Reported Outcomes of an Integrative Pain Management Program Implemented in a Primary Care Safety Net Clinic: a Quasi-experimental Study. J GEN INTERN MED. 2019;34(7):1105-1107. doi:https://doi.org/10.1007/ s11606-019-04868-0

49. Dowell D, Haegerich T, Chou R. No Shortcuts to Safer Opioid Prescribing. N Engl J Med. 2019;380(24):2285-2287. doi:https://doi. org/10.1056/NEJMp1904190

Publisher's Note: Springer Nature remains neutral with regard to jurisdictional claims in published maps and institutional affiliations. 